is equipped with a movable ring holding a contact point. The contact point may be placed a fraction of a minute, or as many minutes as desired, ahead of the minute-hand for the length of treatment to be given. When the minute-hand moves forward enough to touch the contact point, the current from the dry cells in the subbase causes an electro-magnet to release the knife switch which flies open, cutting off all current supply to the apparatus. The switch, when closed, is held by a clip and is so designed as to permit of being used independently of the automatic time device. The switch proper can also be taken off the subbase and used as a substitute for any other switch, while the subbase carrying the clock and holding the cells may be put in some other place more convenient to the operator. As the switch may be used for any kind of current, and for coil equipment, as well as with static machines, wall plates, sinusoidal apparatus, etc., it will afford a means of saving much time and responsibility for one who uses either $x$-ray or electrotherapy.

140 Wabash Arenue.

\section{THE MICROBE OF POLIOMYELITIS.}

FRANCIS HARBITZ, M.D., AND OLAF SCHEEL, M.D. CHRISTIANIA, NORWAY.

In our article concèrning epidemic acute poliomyelitis, we mentioned very briefly $y^{1}$ that bacteria were found in the cerebrospinal fluid in three of the cases which we examined, and that Dr. Geirsvold also succeeded in demonstrating bacteria in the fluid withdrawn by lumbar puncture in twelve cases. Inasmuch as the specificness of these bacteria is a question of great interest, and as other investigators possibly may make similar observations, we desire to supplement our former statements with certain additional facts in regard to the character of the bacteria in question and in regard to other earlier observations in the same field. ${ }^{2}$

The bacteria demonstrated in the spinal fluid were bean-shaped diplococci or tetrads which grew after from two to six days on artificial cultures: In broth they formed short chains of four to six. On agar (ascites, blood or glycerin) they grew as fine gray colonies, and more and more luxuriously as transplantations were made. 'The cocci were very resistant, and the cultures remained alive for weeks and months. They stained easily with diluted carbolfuchsin and with Gram's method; in old cultures the staining with Gram's method was somewhat variable. The cultures were virulent for animals in that they caused atrophy, paresis, emaciation and death.

Perhaps, the same bacterium was found as early as in 1898 by one of us (Harbitz) $;^{3}$ cultures were then obtained but no results followed animal inoculations, and the organism was not studied any farther. On the other hand, Looft and Dethloff, ${ }^{*}$ practicing physicians in Bergen, Norway, in 1901 demonstrated a meningococcus-like microorganism in the spinal fluid of 2 cases of acute poliomyelitis; this organism corresponded in all essentials with the one subsequently found by Dr. Geirsvold. The Bergen physicians also succeeded in obtaining pure cultures. It is well to mention also that

1. The Jocrial A. M. A., O't. 26, 1907.
2. In regard to details see the complete publication: Path. 2. In regard to details see the complete publication: Path.
Anat. Untersuch. iber akute Poliomyelitis u. verwandte Krankheiten Anat. Untersuch. iber akute Poliomyelitis u. verwandte Krankheiten
von den Epidemien in Norwegen, 1903-1906. Videnskabsselskabets von den Fpidemien in Norwegen, 1903
Skrifter, Mathem. Naturvid. Kl.. 1907.

3. Bijlow, Hansen and Harbitz: Norsk Magaz. f. Lägevidens aben, 1898

4. Medicinsk Revue, 1901, and Dethloff : Norsk Magaz. f. Läge4idenskaben, 1905 .
Prof. Fr. Schultze ${ }^{5}$ has found bacteria in the spinal fluid in a few cases of poliomyelitis, but he has not made any closer study of them.

Bacteria have been demonstrated frequently and with so uniform results in acute poliomyelitis that subsequent examinations are desirable. In regard to the specificness of the microbes, not much can be said at the present time, especially because it has not been possible to demonstrate them in the nervous tissues themselves. It should also be borne in mind that similar or morphologically more or less related forms have been found in the spinal fluid in tuberculous meningitis and also in cerebrospinal meningitis. Further investigation should be continued with as fresh material as possible and as early in the attack as it can be done.

\section{SELF-CASTRATION.}

\section{A. E. A. MUMMERY, M.D.} SALINE, MICH.

Mr. L. T.; aged 24; married; occupation, rural mail carrier; was first seen Nov. 6, 1907, at $11: 10 \mathrm{p} . \mathrm{m}$. I found the patient in a semi-conscious condition due to loss of blood; no radial pulse; heart action, 130 ; temperature, $97.4 \mathrm{~F}$. He was lying in a pool of blood coming from a wound in the scrotum, caused by the removal of the left testicle, the cord being cut within the tunica vaginalis. I immediately applied pressure over the pubic region, and after removing clots with my finger, caught and tied vessels with chromicized catgut. The sac was then irrigated with a hot 1-1000 solution of alphazone.

The active hemorrhage being controlled, the cavity was packed with 10 per cent. iodoform gauze, and a light bandage was applied. The heart was stimulated with $1 / 60 \mathrm{gr}$. strychnin sulphate, administered hypodermically, and pain was controlled by scopolamin and morphin. A normal salt enema was also given. Hot water bottles were applied, and in an hour the enema was repeated, the patient's condition improving; pulse, 114, and stronger; temperature, 98 . In two hours the heart action was still improving and the patient was asleep.

At 6 a. m., the pulse was 100 ; temperature, 99.2 ; patient was feeling stronger. A liquid diet was ordered. At $4: 30 \mathrm{p.} \mathrm{m}$., the pulse was 94; temperature, 99.4. Having rested well during the day, the patient was stronger and in good spirits, but complained of some pain.

November 8, 9:30 a. m., pulse, 87 ; temperature, 99.1. The dressings were removed, and the wound was irrigated with alphazone, 1-2000, and packed with iodoform gauze. There were no signs of infection, but there was much ecchymosis of the parts. The irrigations and packing were repeated daily, diminishing the quantity of gauze each time, until on the eighth day, when it was unnecessary. There being a little pus on the ninth day, the wound was irrigated and wiped out with 96 per cent. phenol. Recovery from then on was uneventful.

The circumstances which brought about this deed are as follows: His wife being pregnant, sexual intercourse became very distasteful to her. When young he had formed the habit of masturbation, due chiefly to a long, tight foreskin, and he now resorted to this way of satisfying his passion. Being a zealous church member and reader (not student) of the Bible, he read of the condemnation of Onan, and worried about himself. He read the passage in Matthew 18, 8.9, "If thy hand or thy foot offend thee, cut them off," etc., "If thine eye offend thee, pluck it out," etc. After due consideration, he decided to rid himself of the offending parts. Being left alone for a few days, he carried out his intention, at about 9 p. m., by using a razor. After removing the left testicle he became alarmed at the hemorrhage, which prevented him from unsexing himself completely. At 10:30 p. m., feeling faint, he went to the home of his aunt, about ten rods distant, and had her call his wife and myself. They immediately placed him in bed, where $I$ found him at $11: 10 \mathrm{p} . \mathrm{m}$. 